University of Tennessee Health Science Center

UTHSC Digital Commons

\title{
Hit Identification for PKCZ Inhibitors: Structure-Based Optimization, Virtual Screening, and Biological Evaluation
}

Xiaoxin $\mathrm{Wu}$

University of Tennessee Health Science Center

Follow this and additional works at: https://dc.uthsc.edu/dissertations

Part of the Chemical and Pharmacologic Phenomena Commons, Endocrine System Diseases Commons, Medicinal and Pharmaceutical Chemistry Commons, and the Pharmaceutics and Drug Design Commons

\section{Recommended Citation}

Wu, Xiaoxin (http://orcid.org/0000-0003-0467-9500), "Hit Identification for PKC Based Optimization, Virtual Screening, and Biological Evaluation" (2016). Theses and Dissertations (ETD). Paper 389. http://dx.doi.org/10.21007/etd.cghs.2016.0404.

This Thesis is brought to you for free and open access by the College of Graduate Health Sciences at UTHSC Digital Commons. It has been accepted for inclusion in Theses and Dissertations (ETD) by an authorized administrator of UTHSC Digital Commons. For more information, please contact jwelch30@uthsc.edu. 


\title{
Hit Identification for PKCZ Inhibitors: Structure-Based Optimization, Virtual Screening, and Biological Evaluation
}

\author{
Abstract \\ Protein kinase $\mathrm{C} \zeta(\mathrm{PKC} \zeta)$ is believed to be a promising target for the treatment of some diseases, \\ including inflammatory diseases, obesity and diabetes. Hit identification of PKC $\zeta$ inhibitors was \\ conducted by structure-based modification, virtual screening and biological evaluation. Among all the \\ compounds selected and synthesized, compound JW-1-60A showed moderate activity against PKC $\zeta$ at \\ $30 \mu \mathrm{M}$ and $100 \mu \mathrm{M}$. The molecular modeling studies showed that the binding mode of JW-1-61A was very \\ close to the binding mode of JP-3-149, a reported PKC $\zeta$ inhibitor with very potent activity, which might \\ partially explain the moderate activity of JW-1-61A. Based on the structure of JW-1-60A, we will \\ synthesize a series of its analogs and investigate their selectivity against other kinases in the future.

\section{Document Type} \\ Thesis

\section{Degree Name} \\ Master of Science (MS)

\section{Program} \\ Pharmaceutical Sciences

\section{Research Advisor} \\ Wei Li, Ph.D.

\section{Keywords}

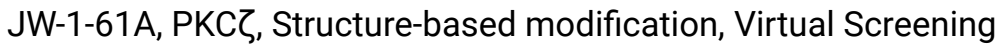

\section{Subject Categories} \\ Chemical and Pharmacologic Phenomena | Diseases | Endocrine System Diseases | Medical Sciences | \\ Medicinal and Pharmaceutical Chemistry | Medicine and Health Sciences | Pharmaceutics and Drug \\ Design | Pharmacy and Pharmaceutical Sciences
}




\title{
Hit Identification for PKC $\zeta$ Inhibitors: Structure-Based Optimization, Virtual Screening, and Biological Evaluation
}

\author{
A Thesis \\ Presented for \\ The Graduate Studies Council \\ The University of Tennessee \\ Health Science Center
}

In Partial Fulfillment

Of the Requirements for the Degree

Master of Science

From The University of Tennessee

By

Xiaoxin $\mathrm{Wu}$

May 2016 
Copyright (C) 2016 by Xiaoxin Wu. All rights reserved. 


\section{ACKNOWLEDGEMENTS}

When I look back over last two years studying at University of Tennessee Health Science Center, I found there are many friends and family members who have journeyed with me as I have worked for this thesis.

First, I would like to express my deepest gratitude to my advisor Dr. Wei Li. I have learned a lot from him over the past two years. His suggestions and insights always inspire me and I firmly believe they will be helpful in my future life. His support and guidance keep me moving on through the rough time.

Secondly, I would like to thank Professor Miller and Professor Yongmei Wang. They kindly served as my committee members and always shared their insights with me. Especially Dr. Miller provided extensive helpful suggestions in the joint meeting every week.

I am also thankful to Dr. Zongzhi Wu, Dr. Dejian Ma, Dr. Yi Xue, Kinsie Arnst, Qinghui Wang, Rachel N Ness and Zongtao Lin, as well as the previous group members, Dr. Jin Wang and Dr. Min. Qinghui Wang, Dr. Zongzhi Wu and Dr. Dong-jin Hwang who synthesized some compounds for my project.

Finally, I would like to thank my parents for everything they have done for me. 


\begin{abstract}
Protein kinase $\mathrm{C} \zeta(\mathrm{PKC} \zeta)$ is believed to be a promising target for the treatment of some diseases, including inflammatory diseases, obesity and diabetes. Hit identification of $\mathrm{PKC} \zeta$ inhibitors was conducted by structure-based modification, virtual screening and biological evaluation. Among all the compounds selected and synthesized, compound JW-1-60A showed moderate activity against PKC $\zeta$ at $30 \mu \mathrm{M}$ and $100 \mu \mathrm{M}$. The molecular modeling studies showed that the binding mode of JW-1-61A was very close to the binding mode of JP-3-149, a reported PKC $\zeta$ inhibitor with very potent activity, which might partially explain the moderate activity of JW-1-61A. Based on the structure of JW1-60A, we will synthesize a series of its analogs and investigate their selectivity against other kinases in the future.
\end{abstract}




\section{TABLE OF CONTENTS}

CHAPTER 1. INTRODUCTION .................................................................................

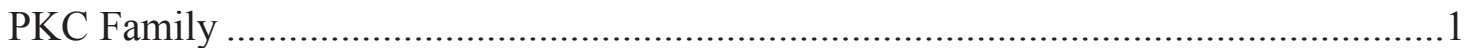

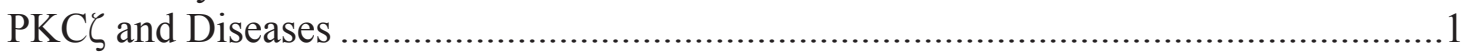

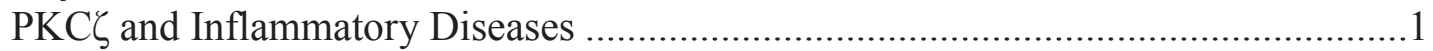

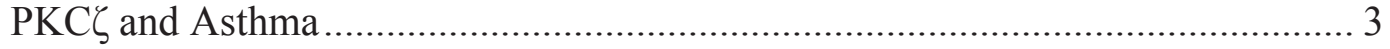

PKC $\zeta$ and Human Osteoarthritic Chondrocytes ............................................... 3

PKC $\zeta$ and Human Sepsis ............................................................................... 3

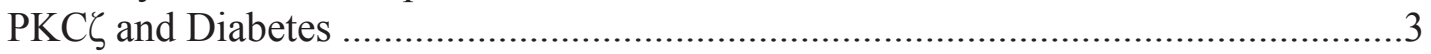

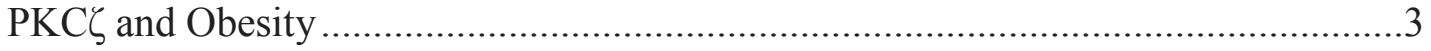

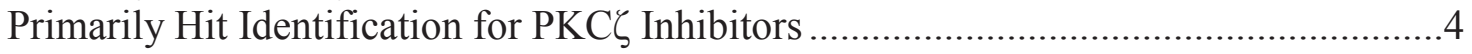

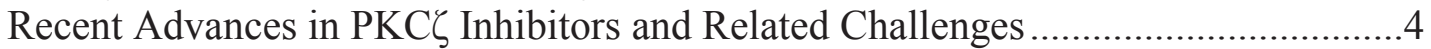

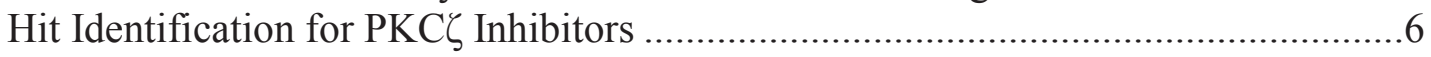

PKC $\zeta$ Hit Identification by Structure Based Optimization ................................ 6

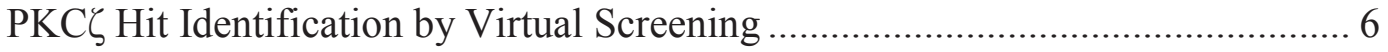

CHAPTER 2. METHODS.....................................................................................8

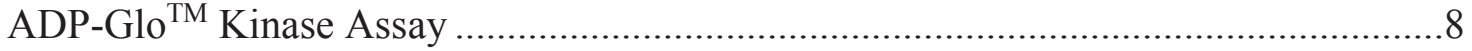

Virtual Screening ................................................................................................. 8

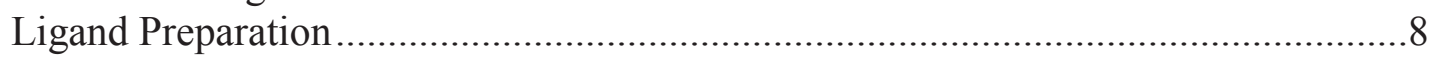

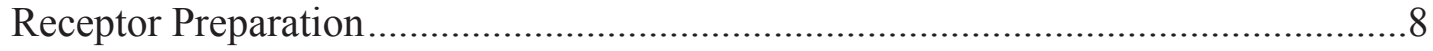

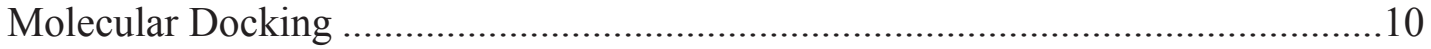

CHAPTER 3. RESULTS ...................................................................................11

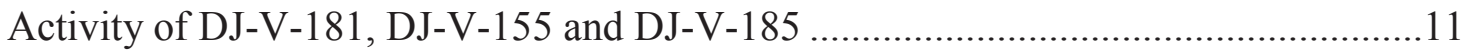

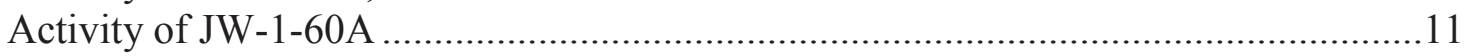

Activity of 25 Compounds Selected From Virtual Screening .....................................11

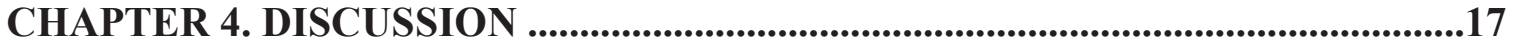

LIST OF REFERENCES ......................................................................................18

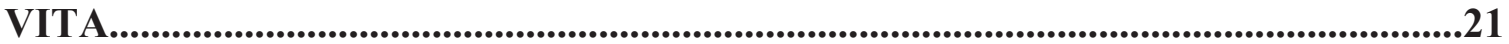




\section{LIST OF FIGURES}

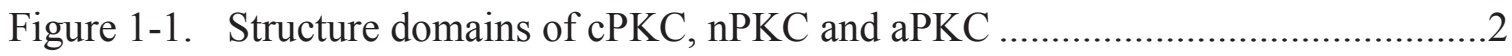

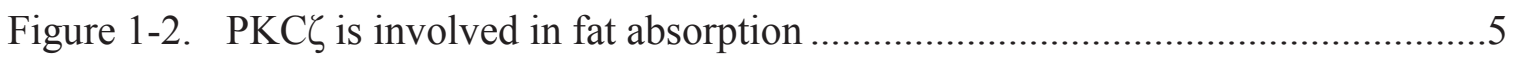

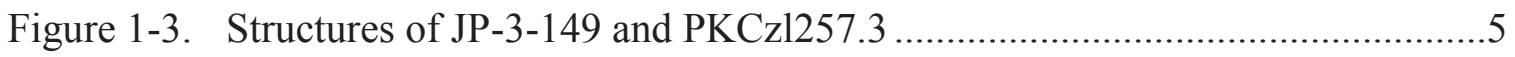

Figure 1-4. Structure optimization of JP-3-149 and molecular structures of DJ-V181, DJ-V-185, DJ-V-155 and JW-1-60A......................................... 7

Figure 2-1. Dose-response curves of Go6850 and JP-3-149 inhibiting PKC $\zeta$

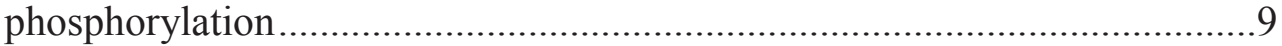

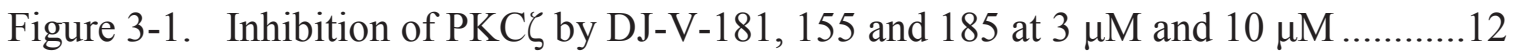

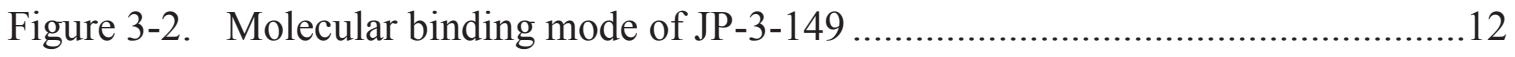

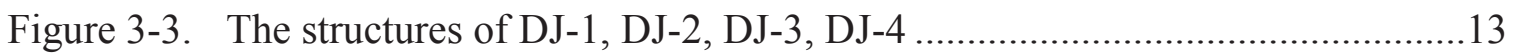

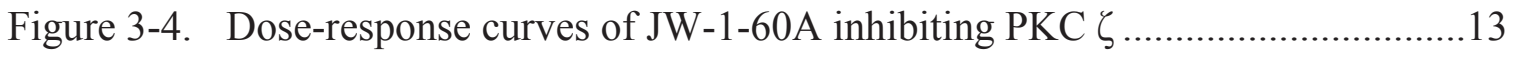

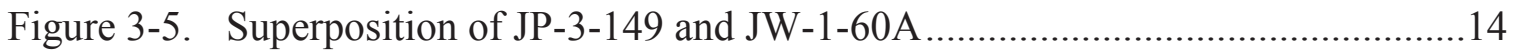

Figure 3-6. Molecular structures of compounds selected from virtual screening ...........15

Figure 3-7. The screen results of the 25 compounds selected from virtual screening.....16 


\section{LIST OF ABBREVIATIONS}

$\begin{array}{ll}\text { APKCs } & \text { Atypical PKCs } \\ \text { CBP } & \text { CREB Binding Protein } \\ \text { CREB } & \text { Cyclic AMP Response Element-Binding Protein } \\ \text { DAG } & \text { Diacylglycerol } \\ \text { ER } & \text { Endoplasmic Reticulum } \\ \text { GLUT4 } & \text { Translocation of Glucose Transporter } 4 \\ \text { IGT } & \text { Impaired Glucose Tolerance } \\ \text { IL } & \text { Interleukin } \\ \text { L-FABP } & \text { Liver Fat Binding Protein } \\ \text { LPS } & \text { Lipopolysaccharide } \\ \text { OA } & \text { Osteoarthritic } \\ \text { PKC } & \text { Protein Kinase C } \\ \text { PIP } 2 & \text { Phosphatidylinositol 4, 5-Bisphosphate } \\ \text { PMA } & \text { Phorbol 12-Myristate 13-Acetate } \\ \text { PS } & \text { Phosphatidylserine } \\ \text { TNF- } \alpha & \text { Tumor Necrosis Factor- } \alpha\end{array}$




\section{CHAPTER 1. INTRODUCTION}

\section{PKC Family}

In 1977, protein kinase C (PKC) was first discovered from bovine cerebellum by Nishizuka's group. They found this new kinase was able to phosphorylate histone [1]. One of his papers published two years later showed that PKC played an important role in cell surface signal transduction and tumor promotion. Besides activated by phosphatidylserine (PS), PKC was also activated by diacylglycerol (DAG) produced during the inositol phospholipids turnover [2]. Recently, the PKC family has been reported to consist of at least ten members, which are classified into three classes: conventional PKCs $(\alpha, \beta \mathrm{I}, \beta \mathrm{II}, \gamma)$, novel PKCs $(\delta, \varepsilon, \mu, \theta$ and $\eta)$, and atypical PKCs $(\zeta$ and $\sqrt{ } / \lambda)[3]$.

Most of conventional PKCs are selectively translocated to the plasma membrane due to their affinity for phosphatidylinositol 4, 5-bisphosphate $\left(\mathrm{PIP}_{2}\right)$. This phospholipid plasma membrane generally has the negative charges on the surface, which is favorable for the recruitment of conventional PKCs. Conventional PKCs contain PKC- $\alpha$ (PRKCA), PKC- $\beta 1, \beta 2$ (PRKCB) and PKC- $\gamma$ (PRKCG). Novel PKCs have the higher affinity for DAG containing membranes. Novel PKCs include PKC- $\delta$ (PRKCD), PKC- $\varepsilon$ (PRKCE), PKC- $\eta$ (PRKCH) and PKC- $\theta$ (PRKCQ). Conventional PKCs and novel PKCs both possess a $\mathrm{C} 1$ domain, which is responsible for binding to the DAG and phorbol 12myristate 13-acetate (PMA), and a C2 domain, which is involved in the calciumdependent phospholipid binding, and a serine/threonine-kinase domain (Figure 1-1).

Atypical PKCs (aPKCs) including $\zeta$ (PRKCZ), $\lambda$ and $\imath$ (PRKCI) are a subfamily of PKC family which require neither $\mathrm{Ca}^{2+}$ nor DAG for activation. Unlike conventional PKCs and novel PKCs which possess two $\mathrm{C} 1$ domains (C1A and $\mathrm{C} 1 \mathrm{~B}$ domain) and $\mathrm{C} 2$ domain, aPKCs have only one atypical $\mathrm{C} 1$ domain and PB1 domain instead. The PB1 domain is responsible for the modular protein-protein interactions, resulting in the regulation of atypical PKCs [4].

\section{PKC $\zeta$ and Diseases}

\section{PKC $\zeta$ and Inflammatory Diseases}

Interestingly, aPKCs, including $\mathrm{PKC} \zeta$ and $\mathrm{PKC} \mathrm{v} / \lambda$, are involved in distinct downstream signaling pathways. Lack of PKC $1 / \lambda$ leads to the lethality of the mouse embryonic stem cells, while $\mathrm{PKC} \zeta$ deficiency severely impairs the activation of the NF$\kappa \mathrm{B}$ pathway, causing the immunological deficiencies of the mice [5-6]. Jorge's group found that PKC $\zeta$ knockout cells showed much less phosphorylation of the RelA in response to tumor necrosis factor- $\alpha$ (TNF- $\alpha$ ). Therefore, they concluded that PKC $\zeta$ was able to phosphorylate RelA. They also believed Ser311, whose phosphorylation is 

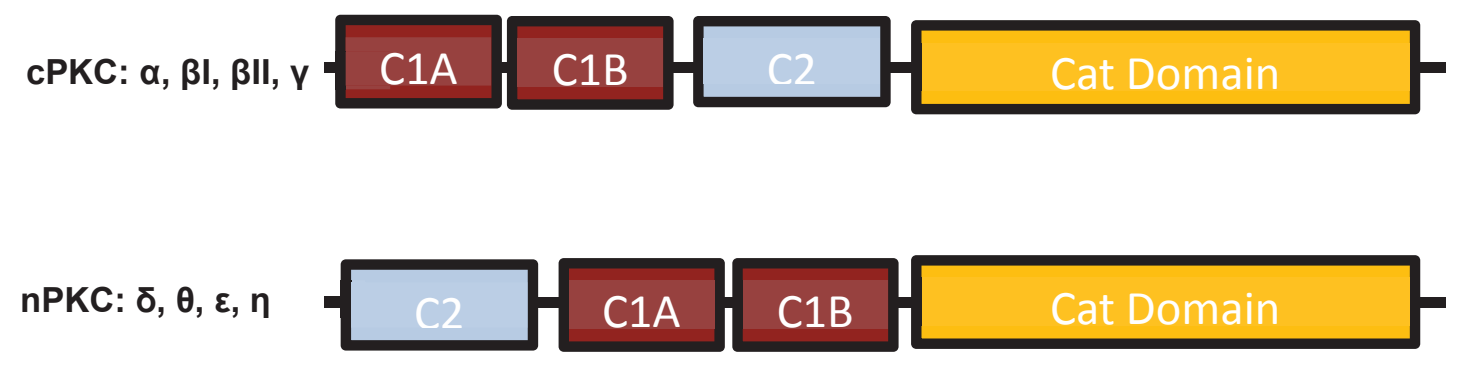

aPKC: $\xi$, T/入

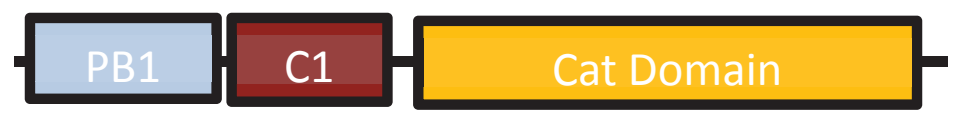

Figure 1-1. Structure domains of $\mathrm{cPKC}, \mathrm{nPKC}$ and $\mathrm{aPKC}$ 
required for the interaction of RelA and the co-activator CREB-binding protein(CBP), plays a critical role in phosphorylation of RelA in NF- $\kappa B$ transcriptional activation [7]. So far extensive studies have been reported that $\mathrm{PKC} \zeta$ is involved in the activation of NF$\kappa \mathrm{B}$ pathway in various cell types, such as B-cells, T helper cells [6, 8-11]. As a result, $\mathrm{PKC} \zeta$ has been proposed as a novel target for treating inflammatory disease such as sepsis [12], psoriasis [13] and asthma [9].

PKC $\zeta$ and Asthma. Pilar Martin's group found increased PKC $\zeta$ level during Th2 differentiation of CD4+ T cells. A lack of $\mathrm{PKC} \zeta$ results in less secretion of Th2 cytokines both in vitro and in vivo, and an obvious impairment in the nuclear translocation and tyrosine phosphorylation of Stat6 activation. Most importantly, PKC $\zeta-/-$ mice show significant inhibition of ovalbumin-induced allergic airway disease, which reveals that $\mathrm{PKC} \zeta$ might be a potential target for treatment of asthma [9].

PKC $\zeta$ and Human Osteoarthritic Chondrocytes. PKC $\zeta$ was also reported to engage the regulation of interleukin (IL) -1beta -induced NF- $\kappa B$ signaling in human osteoarthritic (OA) chondrocytes, subsequently regulating the expression of downstream mediators of cartilage matrix degradation. It has been know that usually $\mathrm{PKC} \zeta$ level is up-regulated in OA patients [14].

PKC $\zeta$ and Human Sepsis. Besides asthma and OA chondrocytes, PKC $\zeta$ plays an important role in human peripheral blood monocytes and macrophages. In particular, Inhibition of $\mathrm{PKC} \zeta$ activity imparts both the activation of NF- $\kappa \mathrm{B}$ and IL- $1 \beta$ gene expression stimulated by bacterial Lipopolysaccharide (LPS). PKC $\zeta$ serves as a downstream signaling kinase of RhoA and upstream kinase of TAK1 in cytokine gene expression in human peripheral blood monocytes and macrophages [15].

\section{PKC $\zeta$ and Diabetes}

$\mathrm{PKC} \zeta$ is involved in insulin-mediated glucose uptake. Insulin stimulates glucose uptake to the plasma membrane by translocation of glucose transporter 4 (GLUT4). Peter's group found that impaired glucose tolerance (IGT) is usually associated with impaired IRS-2-associated PI3 kinase activation and PKC $\zeta$ expression, which may be responsible for the insulin resistance in IGT patients [16].

\section{PKC $\zeta$ and Obesity}

Obesity has become a serious health problem in the United States: nearly $30 \%$ of Americans have obesity. Among all the states, West Virginia, Mississippi and Arkansas have the highest obesity rates at about $35 \%$. If we look at the trend of obesity rates from 1990 to 2014, the obesity rates were keeping increasing. Back to 1990, the average 
obesity rate was about $12 \%$. Right now it has increased more than twofold. Lots of research efforts have been done in the past few decades, while effective prevention and treatment of obesity are still lacking. A new finding reported by Dr. Mansbach's group in department of medicine of University of Tennessee health science center suggested that PKC $\zeta$ plays an important role in fat absorption (Figure 1-2). PKC $\zeta$ phosphorylates Sarb1b with the help of ATP, disassembles this 4-protein complex into its components and releases liver fat binding protein (L-FABP). After that L-FABP is able to bind to intestinal endoplasmic reticulum (ER) and generate the pre-chylomicron transport vesicle, which then exerts its functions in fat absorption. Absence of PKC $\zeta$ or ATP rendered no increase in ER binding or the production of pre-chylomicron transport vesicle. So our hypothesis is that, if we can selectively inhibitor PKC zeta, we are able to stabilize L-FABP and reduce fact absorption [17].

\section{Primarily Hit Identification for PKC $\zeta$ Inhibitors}

\section{Recent Advances in PKC S Inhibitors and Related Challenges}

Some hits from screening libraries or natural compound sources have been reported as $\mathrm{PKC} \zeta$ inhibitors, while up to now no $\mathrm{PKC} \zeta$ selective inhibitors have been reported. One major reason limiting the further exploitation of $\mathrm{PKC} \zeta$ as a novel drug target is the non-selectivity of the reported inhibitors towards the PKC isozymes.

Although aPKCs possess distinctive sequences and structures at the ATP binding pockets compared with conventional PKCs and novel PKCs, which confers the possibility of developing specific inhibitors for aPKCs, the two isozymes of aPKCs, $\mathrm{PKC}$ and $\mathrm{PKC}$, share almost identical residues [18]. Therefore, $\mathrm{PKC} \zeta$ selective inhibitors haven't been reported so far. Actually recently there were some efforts made aiming to discover the hits from virtual screening libraries or natural products. A series of 2-(6-phenyl- $1 \mathrm{H}$ indazol-3-yl)-1H-benzo[d]imidazoles as selective $\mathrm{PKC} \zeta$ were reported and displayed good selectivity towards PKC isoforms, however they displayed inhibitory against a panel of other kinases as well [19]. Among all the compounds, JP-3-149, our previous lab member synthesized it and gave this name, showed the most potent activity against $\mathrm{PKC} \zeta$ with IC50 value of 5.6 nM (Figure 1-3). Jing Wu et al. discovered specific PKC $\zeta$ inhibitor, PKCzI257.3, and evaluated its activity against EGF-induced breast cancer cell chemotaxis. Although it indeed displayed selectivity over conventional PKCs and novel PKCs, no data or studies have been showed that it is able to inhibit the most closely related isozyme $\mathrm{PKCl}$ [20]. Therefore, it is meaningful to discover a novel PKC $\zeta$ scaffold with high activity and selectivity over PKC isozymes. In this pilot project thesis, we mainly used structured-based optimization and virtual screening to identify the hits with novel scaffolds for $\mathrm{PKC} \zeta$ inhibitors. 


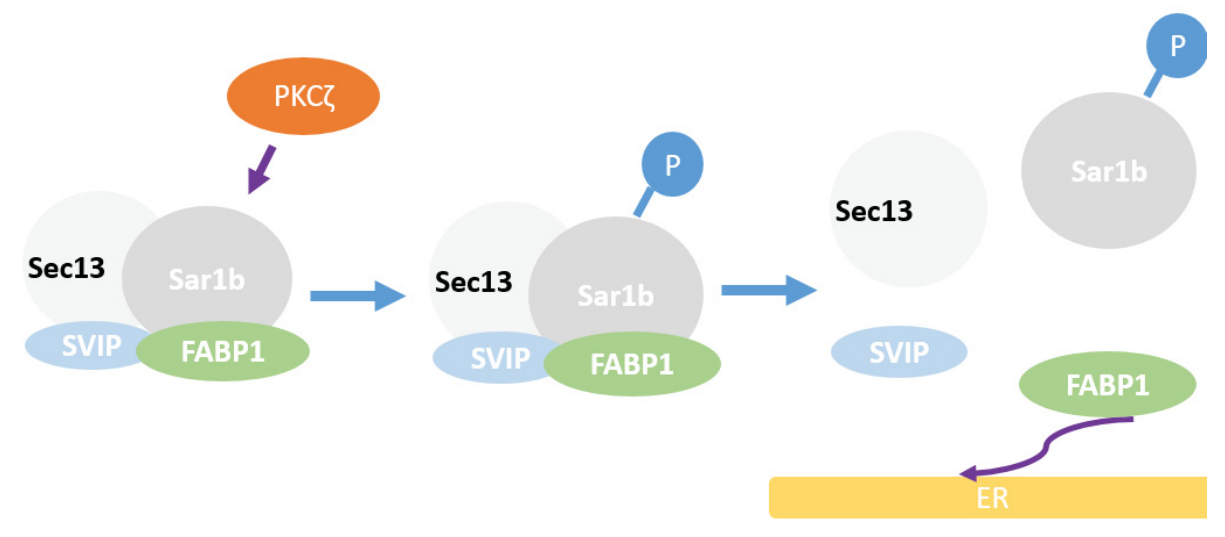

Figure 1-2. $\quad \mathrm{PKC} \zeta$ is involved in fat absorption
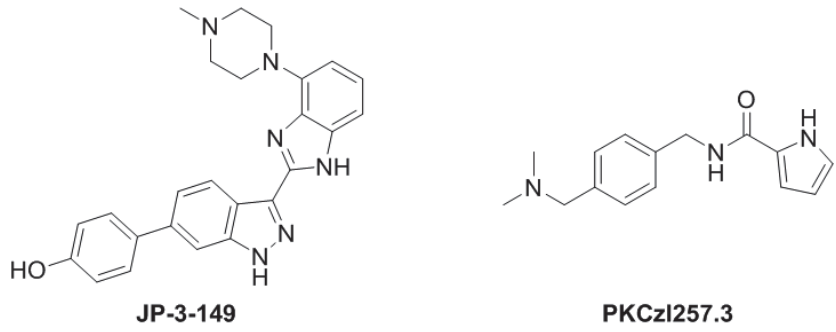

Figure 1-3. Structures of JP-3-149 and PKCzl257.3 


\section{Hit Identification for PKC $\zeta$ Inhibitors}

PKC $\zeta$ Hit Identification by Structure Based Optimization. One way we adopted to identify the hits for PKC $\zeta$ inhibition was to optimize the structures of reported compounds. Considering the highly potent activity of JP-3-149, we believe it would be a very good scaffold for us to modify. So what we did was basically moving this nitrogen in the imidazole to the 4 or 6 position on phenyl ring of the benzimidazole ring

(Figure 1-4). Here are the structures of the compounds we came up with. The compounds were made by Dr. Dong-jin Hwang in Dr. Miller's group. For the DJ-V-181, we kept the rest part of DJ-V-181 the same as what JP-3-149 has, and tried to see if this new scaffold would make any changes to the activity. DJ-V-155 has a phenol attached to benzimidazole ring instead of a N-methyl piperazine ring. DJ-V-185 has a methoxylphenol instead of just a phenol. Similarly, we designed and synthesized JW-1$60 \mathrm{~A}$ which possesses a methyl piperazine ring and a phenyl moiety at the other end. And from the molecular docking studies, JW-1-60A showed a very interesting binding mode, which is very similar to what JP-3-149 showed.

PKC $\zeta$ Hit Identification by Virtual Screening. Recently, extensive reports showed that virtual screening has become a very popular technique at the initial stage of drug discovery due to its low cost and high efficiency. Lots of structures have been identified as novel leads for the drug targets using this technique. In this pilot project, a receptor-based virtual screening was performed to identify novel PKC $\zeta$ inhibitors. About $360 \mathrm{~K}$ compounds from a library of University of Cincinnati were used to undergo the virtual screening. The compounds were first filtered according to Lipinski' Rule and drug like properties. Crystal structure 3EZR was downloaded from PDB and prepared. The Virtual Screening workflows includes glide HTVS, glide SP and glide XP. Only 10\% of the compounds with the best docking scores were retained and advance into the next round. After these docking steps, twenty five compounds were picked and evaluated for their activity against $\mathrm{PKC} \zeta$ via enzyme based assay.

Among all the compounds selected and synthesized, compound JW-1-60A showed the most potency with an IC50 value close to $50 \mu \mathrm{M}$. Currently our project is still underway. A series of compounds based on the structure of JW-1-60A may further be designed, synthesized and investigated for their activity. Their selectivity against the general panel of kinases, including the most closely related isoenzyme $\mathrm{PKCl}$ will also be investigated. If they show selectivity towards the other kinases, cell assays and structure modifications will be performed as the next steps. 

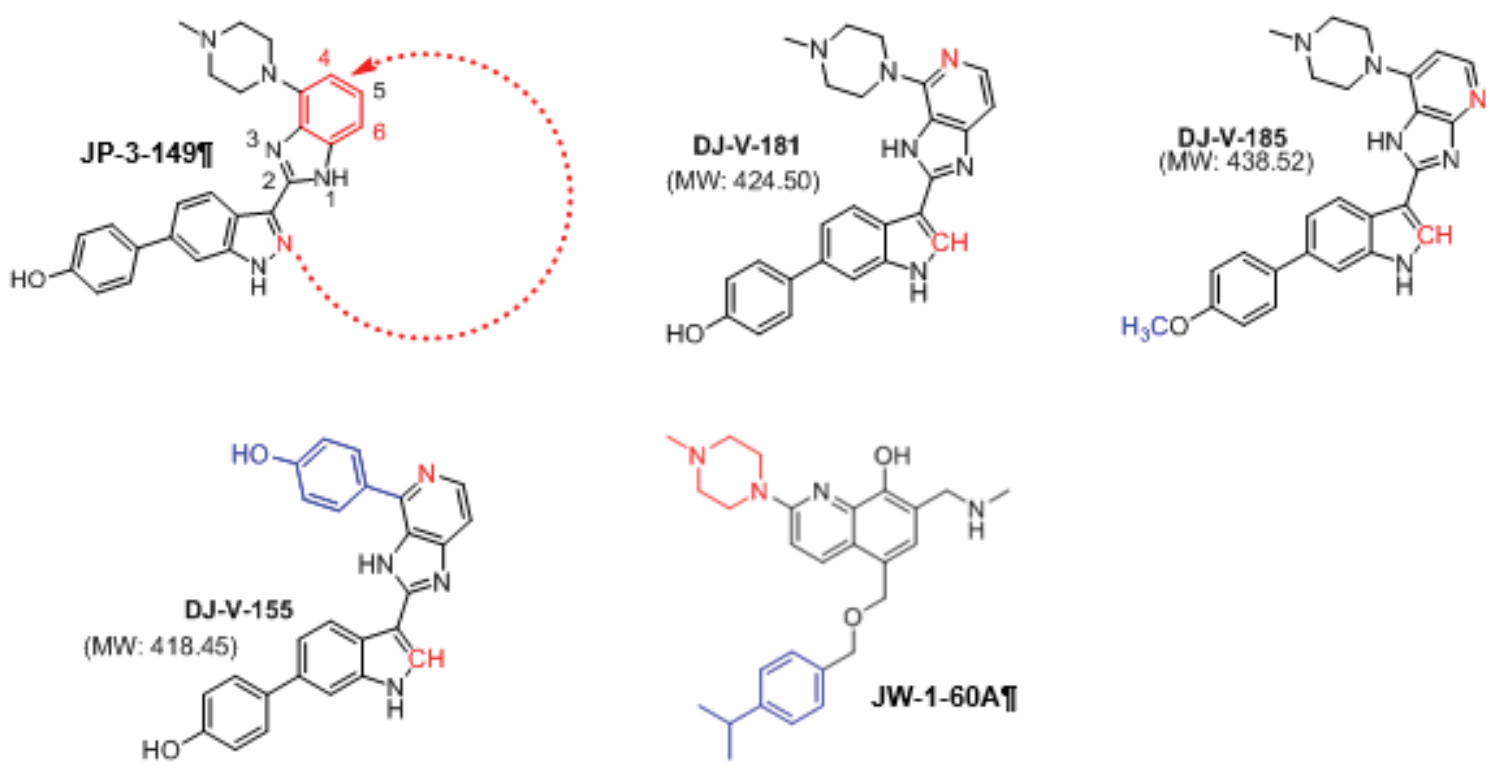

Figure 1-4. Structure optimization of JP-3-149 and molecular structures of DJ-V181, DJ-V-185, DJ-V-155 and JW-1-60A. 


\section{CHAPTER 2. METHODS}

\section{ADP-Glo ${ }^{\text {TM }}$ Kinase Assay}

Before testing the activity of the compounds, first we performed the method optimization for the ADP-Glo ${ }^{\mathrm{TM}}$ Kinase Assay by optimizing the incubation time, reaction volume and the ratio of components. The activity of two PKC $\zeta$ inhibitors, Go6850 and JP-3-149, was evaluated to see if the assay worked well (Figure 2-1).

Briefly, the activities of the compounds were measured by quantifying the amount of ADP produced during the reaction. The assay was based on the protocol provided by Promega with some modifications. 1 x Reaction buffer A supplemented with $50 \mu$ M DDT containing $10 \mu \mathrm{L}$ of kinase $(10 \mathrm{ng}), 5 \mu \mathrm{L}$ of CREBtide $(1 \mathrm{ng}), 5 \mu \mathrm{L}$ of pure ATP $(50 \mu \mathrm{M}$, final concentration) and $5 \mu \mathrm{L}$ of inhibitor (achieved through third-fold serial dilution) was used as the reaction buffer. The mixtures were incubated at the room temperature for 3 hours or longer time. After that, $5 \mu \mathrm{L}$ of ADP-Glo ${ }^{\mathrm{TM}}$ reagent was added to each well and the mixtures were incubated at room temperature for 40 minutes or any desired time. Then, $10 \mu \mathrm{L}$ of Kinase Detection Reagent was added to each well and the mixtures were incubated at room temperature for 30 to 60 minutes. The luminescence of the product was read with BioTek. The average background value was subtracted from the resulting values.

\section{Virtual Screening}

\section{Ligand Preparation}

A virtual drug discovery center library from the University of Cincinnati containing 362,910 compounds was used to undergo the virtual screening via VS Workflow module (Schrodinger, LLC, New York, NY, 2015). The compounds were first filtered prior to docking according to Lipinski' Rule and drug like properties. As a result, the compounds containing some reactive functional groups, such as acyl halides, phosphinyl halides and disulfides were removed. After that, all the compounds were prepared and generated their ionization and tautomeric states with Epik at $7.0 \pm 2.0 \mathrm{pH}$ units. Conformers of the compounds were generated by OPLS_2005 force field, specially using the ConfGen conformational sampling algorithm.

\section{Receptor Preparation}

X-ray structure 3EZR was downloaded from PDB and underwent the protein preparation. The grid of ATP binding site was defined based on the binding site of the reported active inhibitor [21]. Both the VdW radius scale factor and the charge scale factor were specified at 1.0 for the selected residues. After that four hydrogen bond 
Inhibition of PKC-孔 By Go6850

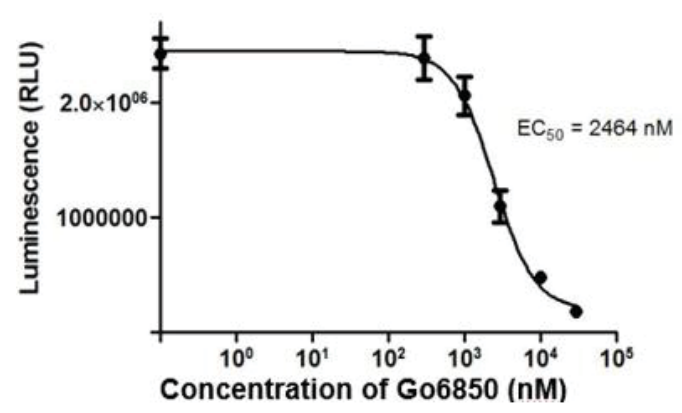

Inhibition of PKC- $\zeta$ By JP-3-149

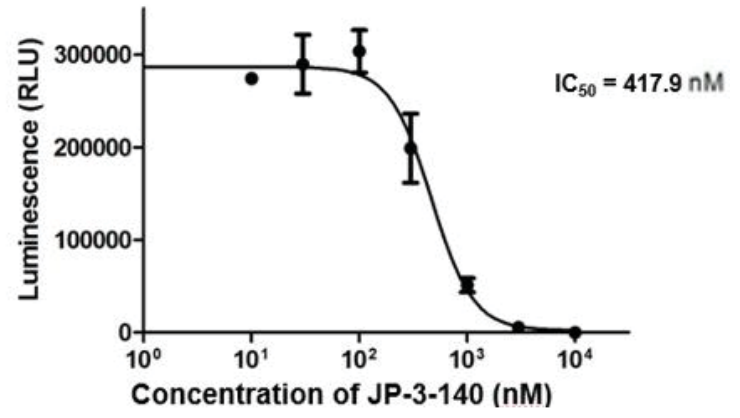

Figure 2-1. Dose-response curves of Go6850 and JP-3-149 inhibiting PKC phosphorylation 
constraints were set. Specifically, the oxygen atoms of Glu 331, Val 333, Glu 300 and Asp 337 were picked in the Workspace. OPLS_2005 force field was used to computer partial charges.

\section{Molecular Docking}

The prepared compounds and generated grid described above were specified in the Ligand section and Receptor grid section, respectively. OPLS2001 was selected as force field with post-docking minimizations. Docking with Glide HTVS, Glide SP and Glide XP were all selected. And in each docking method, flexible docking was chosen and at least 3 constrains among total 4 constrains were used for the grid during docking process. Only $10 \%$ of the compounds with the best docking scores were allowed to be kept and advance into the next round. All the good scoring states of each ligand docked with Glide HTVS and SP were retained, while only the best scoring pose was retained for compounds docked with Glide XP. 


\section{CHAPTER 3. RESULTS}

\section{Activity of DJ-V-181, DJ-V-155 and DJ-V-185}

After the assay worked, we tested the activity of these three compounds. To our surprise, none of them showed significant activity at 10 or $3 \mu \mathrm{M}$ against $\mathrm{PKC}$-zeta (Figure 3-1). The positive control, JP-3-149, showed almost 100\% inhibition

Figure 3-2 shows the binding mode of JP-3-149. This nitrogen in the imidazole of JP-3-149 does form hydrogen bond with Tyr332, so we think it may be very critical for its binding and this might explain why DJ-V-181, DJ-V-155 and DJ-V-185 didn't show activity against PKC-zeta at 10 or $3 \mu \mathrm{M}$.

Based on this conclusion and the molecular studies, another four compounds were designed. Instead of removing the nitrogen away from the indazole ring, we are trying to add an extra nitrogen to the benzimidazole. Besides, some modifications on the methyl piperazine ring will also be conducted to improve the hydrogen bindings (Figure 3-3).

\section{Activity of JW-1-60A}

As Figure 3-4 shows, at $10 \mu \mathrm{M} J W-1-60 \mathrm{~A}$ didn't show any inhibition either, while at $30 \mu \mathrm{M}$ and $100 \mu \mathrm{M}$, we can see its significant inhibition against PKC- $\zeta$. The binding mode of JW-1-60A was examined by molecular modeling studies using Schrodinger Molecular Modeling Suite 2015. Figure 3-5 shows the overall binding modes of JW-1-60A (orange tube model) and JP-3-149 (purple tube model) in the ATPbinding site pocket of the PKC $\zeta$ (3EZV). In particular, their piperazine rings approach deep into the hinge region. At the other end, their phenyl moieties place at almost the same location. We believe their similar binding modes partially explain the activity of JW-1-60A. They both extend from the hinge region and reach another pocket formed basically by two loops, and band in the middle. As reported by the John's group, JP-3149 would form one hydrogen bond with Asp 331 and two hydrogen bonds with Val 332, respectively. An additional hydrogen bond between its phenol and Glu 300 of helix C was also observed as well. However, JW-1-60A shows less interactions compared with JP-3-149. Only one hydrogen bond with Tyr 332 is formed. Interestingly, the overall location of JW-1-60A is shallower inside the pocket than the location of JP-3-149, which we believe might be another factor leading to the worse activity of JW-1-60A than JP-3149.

\section{Activity of 25 Compounds Selected from Virtual Screening}

Figure 3-6 shows the structures of the selected compounds. Unfortunately, none of the compound selected from Virtual Screening showed significant activity against $\mathrm{PKC} \zeta$ at $10 \mu \mathrm{M}$ or $3 \mu \mathrm{M}$. The positive control used was Go6850 (Figure 3-7). 
Inhibition of PKC-ろ By DJ-V-181,155,185

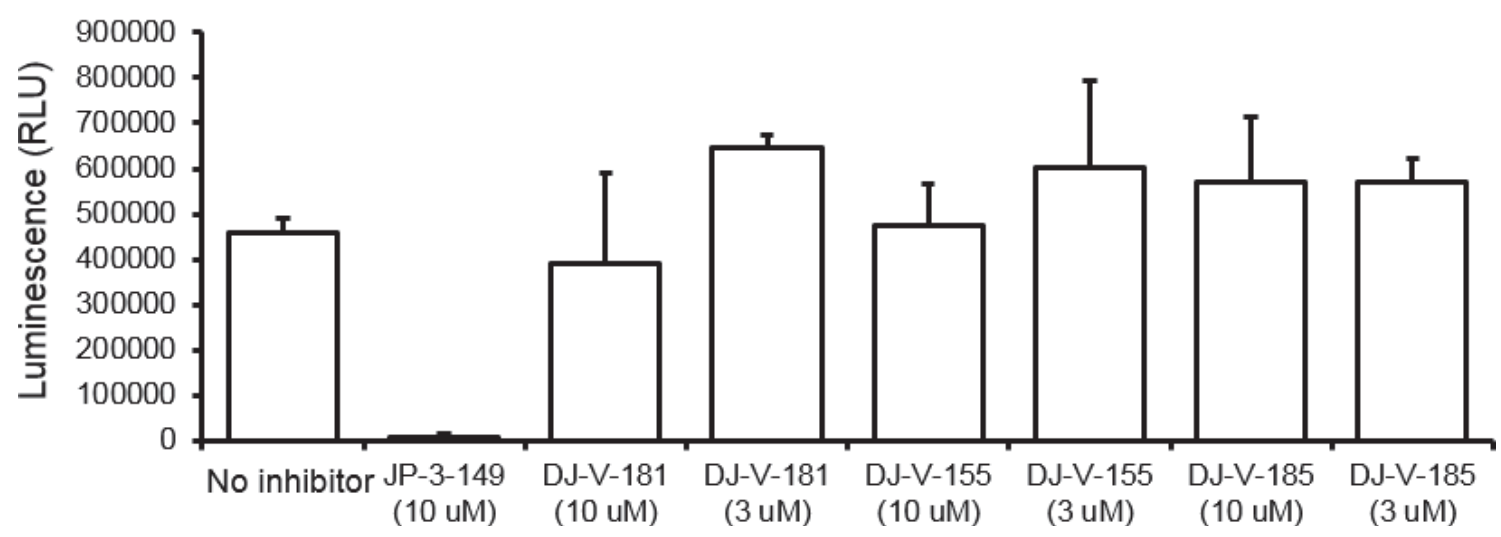

Figure 3-1. Inhibition of PKC $\zeta$ by DJ-V-181, 155 and 185 at $3 \mu \mathrm{M}$ and $10 \mu \mathrm{M}$

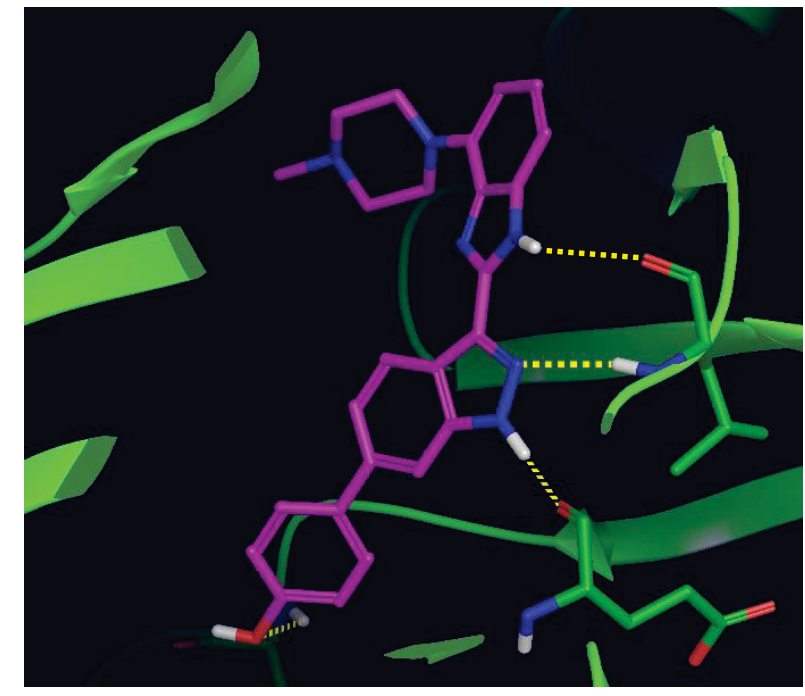

Figure 3-2. Molecular binding mode of JP-3-149 


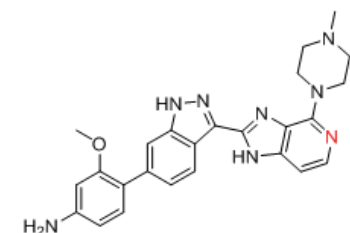

DJ-1

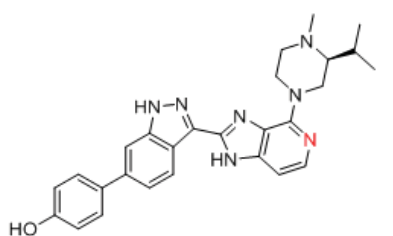

DJ-2

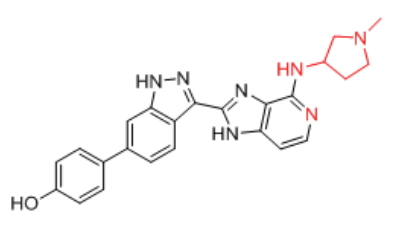

DJ-3

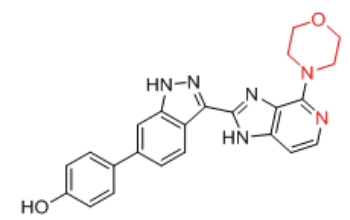

DJ-4

Figure 3-3. The structures of DJ-1, DJ-2, DJ-3, DJ-4

Inhibition of PKC- $\zeta$ by JW-1-60A

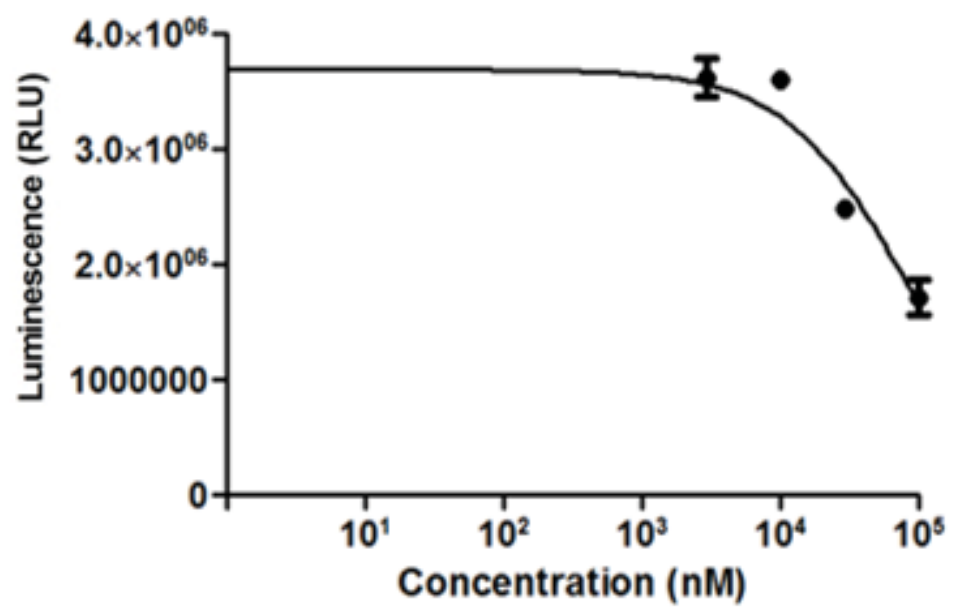

Figure 3-4. Dose-response curves of JW-1-60A inhibiting PKC 


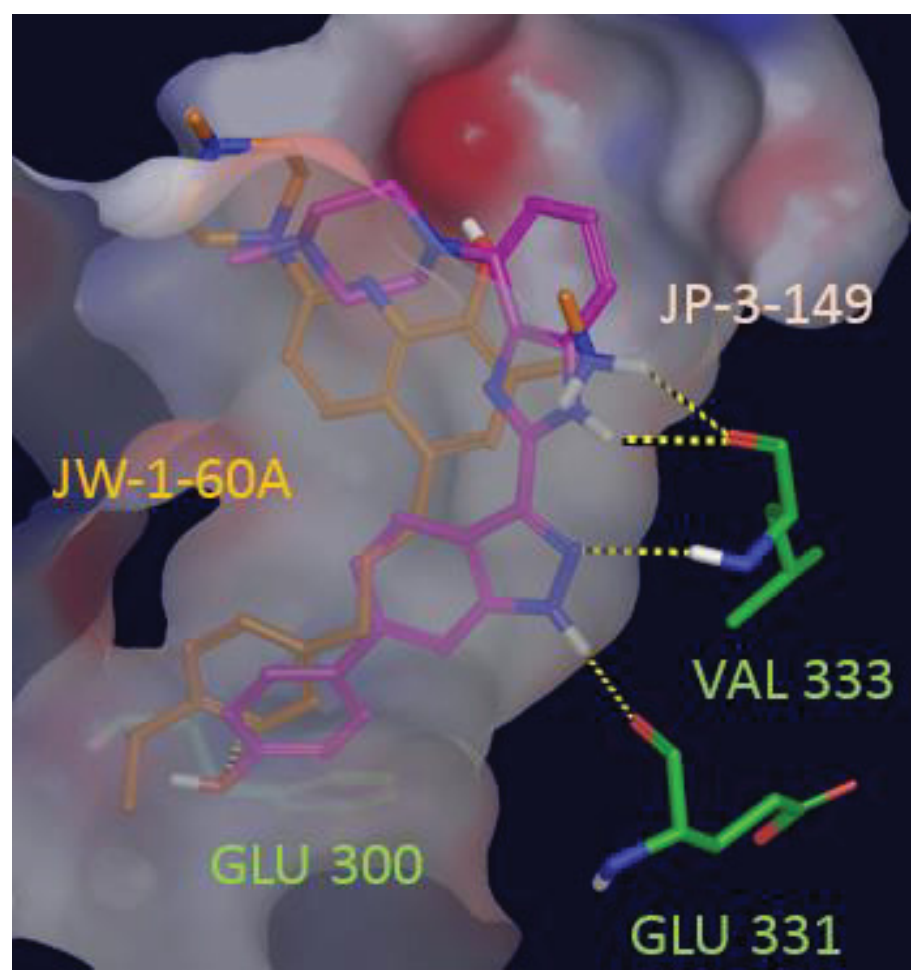

Figure 3-5. Superposition of JP-3-149 and JW-1-60A 


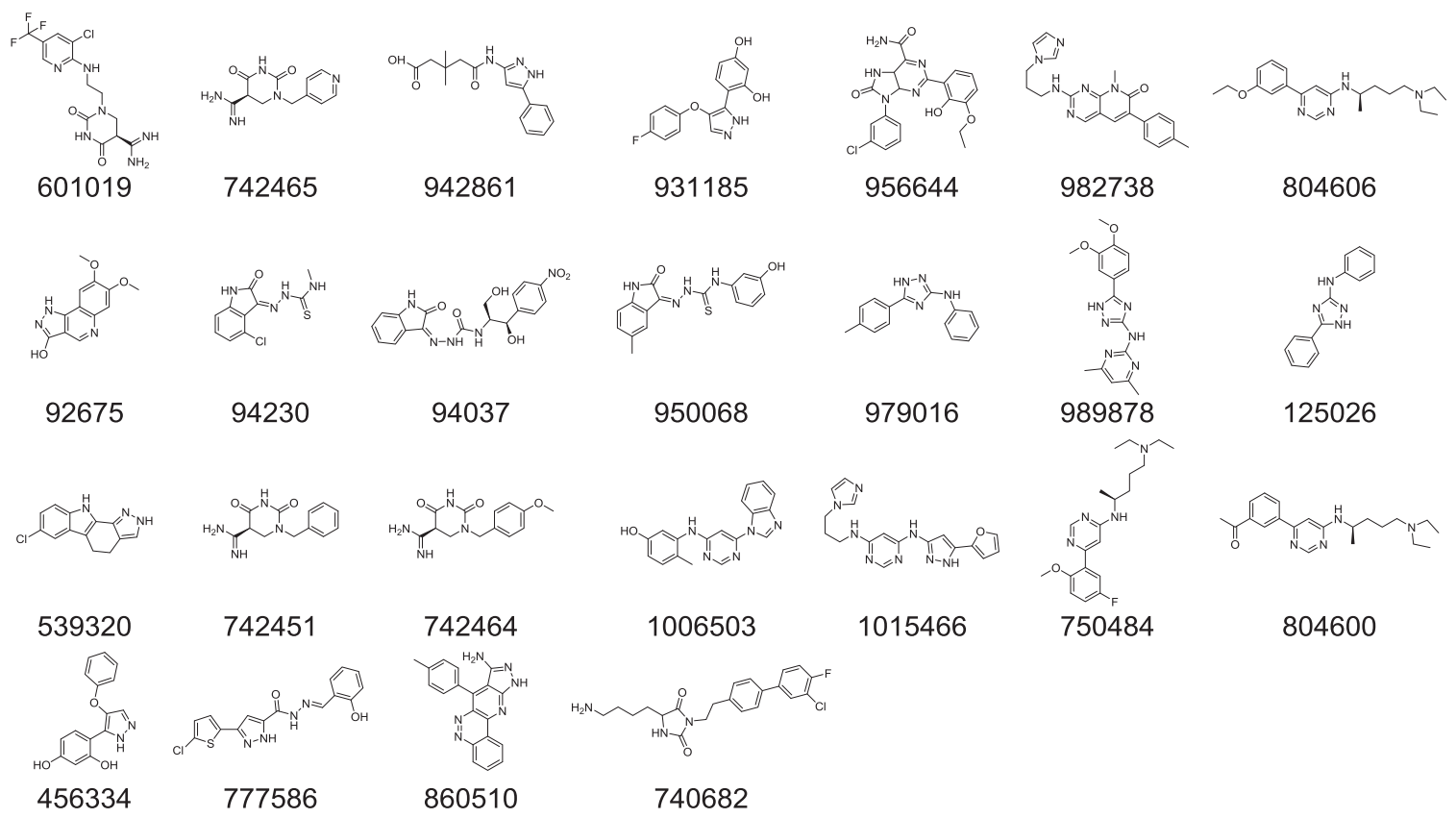

Figure 3-6. Molecular structures of compounds selected from virtual screening 
Inhibition of PKC- $\zeta$

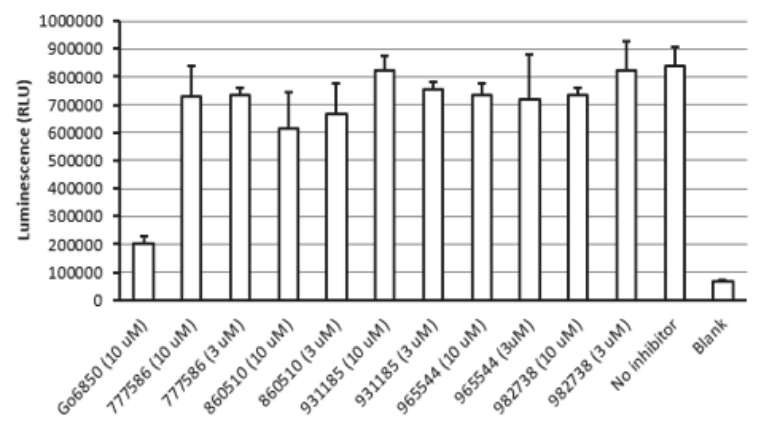

Inhibition of PKC- $\zeta$

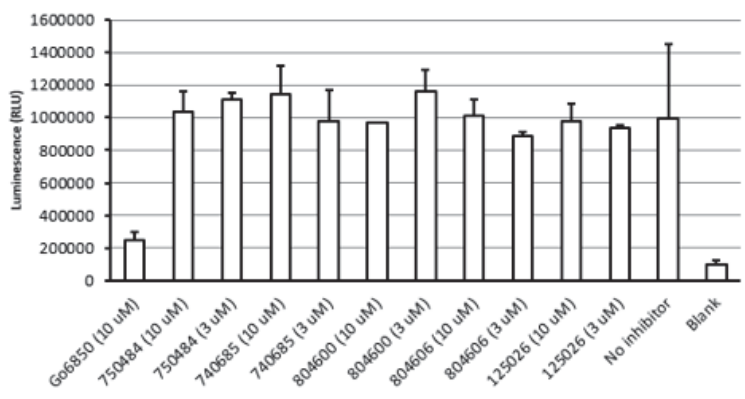

Inhibition of PKC- $\zeta$

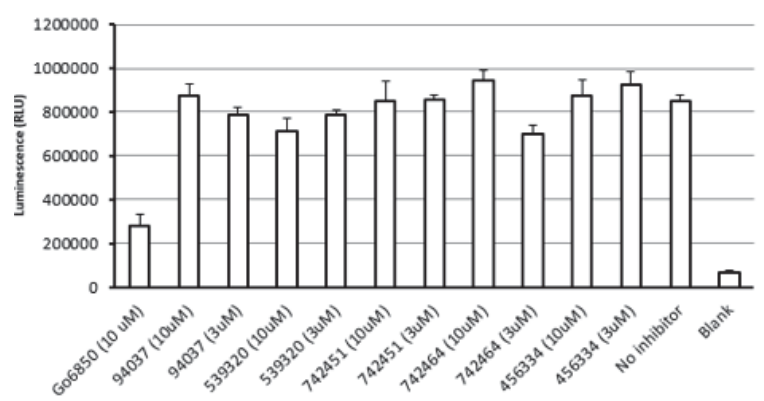

Inhibition of PKC- $\zeta$

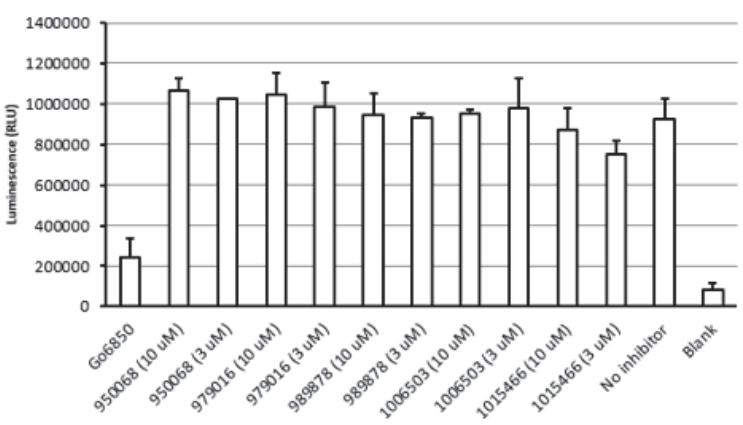

Inhibition of PKC-乙

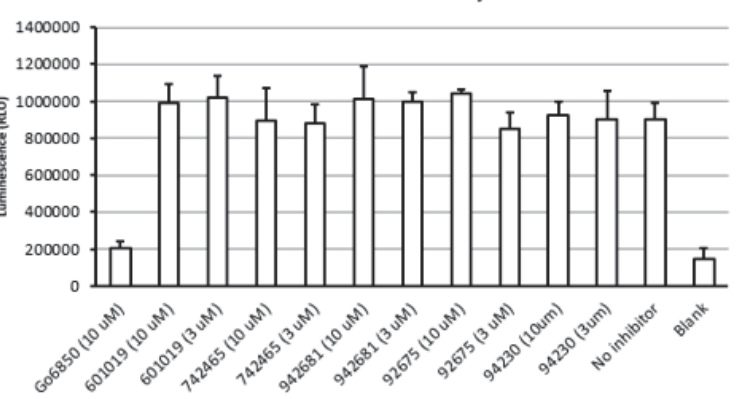

Figure 3-7. The screen results of the 25 compounds selected from virtual screening 


\section{CHAPTER 4. DISCUSSION}

Novel PKC $\zeta$ inhibitor, JW-1-60A, was designed and synthesized. JW-1-60A showed moderate activity against $\mathrm{PKC} \zeta$. Molecular modeling studies were performed to examine the binding of JW-1-60A in PKC $\zeta$ crystal structure. Based on the binding mode of JW-1-60A and JP-3-149 (Figure 3-5), we came up with some ideas about future modifications of JW-1-60A. Like we can change the isopropyl phenyl to phenol to take advantage of the interactions with Glu 300. Or we can incorporate an indazole ring to the linker in order to form hydrogen binds with Val 333 and Glu 331, and also make the structure more rigid.

The binding mode of JW-1-60A was very close to the binding mode of JP-3-149, which might partially explain the moderate activity of JW-1-60A. In summary, JW-1$60 \mathrm{~A}$ represents a novel scaffold of $\mathrm{PKC} \zeta$ inhibitors, which might be used to generate a series of its analogs with potent activity and high in the future. Furthermore, this compound will be investigated its selectivity against the other isoforms of PKC family and other kinases later. 


\section{LIST OF REFERENCES}

1. Inoue, M.; Kishimoto, A.; Takai, Y.; Nishizuka, Y. Studies on a cyclic nucleotideindependent protein kinase and its proenzyme in mammalian tissues. II.

Proenzyme and its activation by calcium-dependent protease from rat brain. The Journal of biological chemistry, 1977, 252, 7610-7616.

2. Nishizuka, $\mathrm{Y}$. The role of protein kinase $\mathrm{C}$ in cell surface signal transduction and tumour promotion. Nature, 1984, 308, 693-698.

3. Mochly-Rosen, D.; Basbaum, A. I.; Koshland, D. E., Jr. Distinct cellular and regional localization of immunoreactive protein kinase $\mathrm{C}$ in rat brain. Proceedings of the National Academy of Sciences of the United States of America, 1987, 84, 4660-4664.

4. Lopez-Garcia, L. A.; Schulze, J. O.; Frohner, W.; Zhang, H.; Suss, E.; Weber, N.; Navratil, J.; Amon, S.; Hindie, V.; Zeuzem, S.; Jorgensen, T. J. D.; Alzari, P. M.; Neimanis, S.; Engel, M.; Biondi, R. M. Allosteric Regulation of Protein Kinase PKC zeta by the N-Terminal C1 Domain and Small Compounds to the PIFPocket. Chem Biol, 2011, 18, 1463-1473.

5. Bandyopadhyay, G.; Standaert, M. L.; Sajan, M. P.; Kanoh, Y.; Miura, A.; Braun, U.; Kruse, F.; Leitges, M.; Farese, R. V. Protein kinase C-lambda knockout in embryonic stem cells and adipocytes impairs insulin-stimulated glucose transport. Molecular endocrinology, 2004, 18, 373-383.

6. Leitges, M.; Sanz, L.; Martin, P.; Duran, A.; Braun, U.; Garcia, J. F.; Camacho, F.; Diaz-Meco, M. T.; Rennert, P. D.; Moscat, J. Targeted disruption of the zeta PKC gene results in the impairment of the NF-kappa B pathway. Mol Cell, 2001, $8,771-780$.

7. Duran, A.; Diaz-Meco, M. T.; Moscat, J. Essential role of RelA Ser311 phosphorylation by zetaPKC in NF-kappaB transcriptional activation. The EMBO journal, 2003, 22, 3910-3918.

8. Martin, P.; Duran, A.; Minguet, S.; Gaspar, M. L.; Diaz-Meco, M. T.; Rennert, P.; Leitges, M.; Moscat, J. Role of zeta PKC in B-cell signaling and function. The EMBO journal, 2002, 21, 4049-4057.

9. Martin, P.; Villares, R.; Rodriguez-Mascarenhas, S.; Zaballos, A.; Leitges, M.; Kovac, J.; Sizing, I.; Rennert, P.; Marquez, G.; Martinez, A. C.; Diaz-Meco, M. T.; Moscat, J. Control of T helper 2 cell function and allergic airway inflammation by PKCzeta. Proceedings of the National Academy of Sciences of the United States of America, 2005, 102, 9866-9871. 
10. Gruber, T.; Fresser, F.; Jenny, M.; Uberall, F.; Leitges, M.; Baier, G. PKCtheta cooperates with atypical PKCzeta and PKCiota in NF-kappaB transactivation of T lymphocytes. Molecular immunology, 2008, 45, 117-126.

11. San-Antonio, B.; Iniguez, M. A.; Fresno, M. Protein kinase Czeta phosphorylates nuclear factor of activated $\mathrm{T}$ cells and regulates its transactivating activity. The Journal of biological chemistry, 2002, 277, 27073-27080.

12. Peng, Y.; Sigua, C. A.; Karsonovich, C.; Murr, M. M. Protein kinase C-zeta (PKC-zeta) regulates Kupffer cell apoptosis during experimental sepsis. Journal of gastrointestinal surgery : official journal of the Society for Surgery of the Alimentary Tract, 2007, 11, 1712-1721.

13. Huang, X.; Begley, M.; Morgenstern, K. A.; Gu, Y.; Rose, P.; Zhao, H.; Zhu, X. Crystal structure of an inactive Akt2 kinase domain. Structure, 2003, 11, 21-30.

14. Chockalingam, P. S.; Varadarajan, U.; Sheldon, R.; Fortier, E.; LaVallie, E. R.; Morris, E. A.; Yaworsky, P. J.; Majumdar, M. K. Involvement of protein kinase Czeta in interleukin-1beta induction of ADAMTS-4 and type 2 nitric oxide synthase via NF-kappaB signaling in primary human osteoarthritic chondrocytes. Arthritis and rheumatism, 2007, 56, 4074-4083.

15. Huang, X.; Chen, L. Y.; Doerner, A. M.; Pan, W. W.; Smith, L.; Huang, S.; Papadimos, T. J.; Pan, Z. K. An atypical protein kinase C (PKC zeta) plays a critical role in lipopolysaccharide-activated NF-kappa B in human peripheral blood monocytes and macrophages. Journal of immunology, 2009, 182, 58105815.

16. Vollenweider, P.; Menard, B.; Nicod, P. Insulin resistance, defective insulin receptor substrate 2-associated phosphatidylinositol-3' kinase activation, and impaired atypical protein kinase $\mathrm{C}$ (zeta/lambda) activation in myotubes from obese patients with impaired glucose tolerance. Diabetes, 2002, 51, 1052-1059.

17. Siddiqi, S.; Mansbach, C. M., 2nd Phosphorylation of Sar1b protein releases liver fatty acid-binding protein from multiprotein complex in intestinal cytosol enabling it to bind to endoplasmic reticulum (ER) and bud the pre-chylomicron transport vesicle. The Journal of biological chemistry, 2012, 287, 10178-10188.

18. Steinberg, S. F. Structural basis of protein kinase C isoform function. Physiological reviews, 2008, 88, 1341-1378.

19. Trujillo, J. I.; Kiefer, J. R.; Huang, W.; Thorarensen, A.; Xing, L.; Caspers, N. L.; Day, J. E.; Mathis, K. J.; Kretzmer, K. K.; Reitz, B. A.; Weinberg, R. A.; Stegeman, R. A.; Wrightstone, A.; Christine, L.; Compton, R.; Li, X. 2-(6-Phenyl1H-indazol-3-yl)-1H-benzo[d]imidazoles: design and synthesis of a potent and 
isoform selective PKC-zeta inhibitor. Bioorganic \& medicinal chemistry letters, 2009, 19, 908-911.

20. Wu, J.; Zhang, B.; Wu, M.; Li, H.; Niu, R.; Ying, G.; Zhang, N. Screening of a PKC zeta-specific kinase inhibitor PKCzI257.3 which inhibits EGF-induced breast cancer cell chemotaxis. Investigational new drugs, 2010, 28, 268-275.

21. Trujillo, J. I.; Kiefer, J. R.; Huang, W.; Thorarensen, A.; Xing, L.; Caspers, N. L.; Day, J. E.; Mathis, K. J.; Kretzmer, K. K.; Reitz, B. A.; Weinberg, R. A.; Stegeman, R. A.; Wrightstone, A.; Christine, L.; Compton, R.; Li, X. 2-(6-Phenyl$1 \mathrm{H}$-indazol-3-yl)-1H-benzo[d]imidazoles: Design and synthesis of a potent and isoform selective PKC-zeta inhibitor. Bioorg. Med. Chem. Lett., 2009, 19, 908911. 


\section{VITA}

Xiaoxin Wu was born in Zhejiang Province, China, in 1991. He entered China Pharmaceutical University in 2009 and earned a Bachelor of Science degree in Pharmacy in 2013. After that he joined Dr. Wei Li's lab at University of Tennessee Health Science Center in pursuit of a Master degree in Pharmaceutical Sciences. 